\title{
The Dominance of Behavioural Activation over Behavioural Inhibition in Conduct Disordered Boys with or without Attention Deficit Hyperactivity Disorder
}

\author{
Walter Matthys and Stephanie H. M. van Goozen \\ University Hospital Utrecht and Utrecht University, The Netherlands \\ Han de Vries \\ Utrecht University, The Netherlands \\ Peggy T. Cohen-Kettenis and Herman van Engeland \\ University Hospital Utrecht and Utrecht University, The Netherlands
}

\begin{abstract}
On the basis of Gray's theory, Quay suggested that conduct disorder (CD) is associated with a Behavioural Activation System (BAS) that dominates over the Behavioural Inhibition System (BIS), whereas attention deficit hyperactivity disorder (ADHD) is characterised by an underactive BIS. Two studies were conducted to test the hypothesis that the dominance of the BAS over the BIS is more pronounced in CD comorbid with ADHD (CD/ADHD) than in CD alone. First of all, a response perseveration task was used, i.e. the door-opening task (Daugherty \& Quay, 1991). In this game, the subject chooses either to open the next door or to stop playing; there is a steadily increasing ratio of punished responses to rewarded responses and a large number of doors opened is indicative of response perseveration. As expected, a steady increase in the number of doors opened was found across normal control (NC) boys, $\mathrm{CD}$ boys, and $\mathrm{CD} / \mathrm{ADHD}$ boys ( $\mathrm{NC}<\mathrm{CD}<\mathrm{CD} / \mathrm{ADHD}$ ). Second, the dominance of the BAS over the BIS was examined by observing the social behaviour of the child in interaction with a research assistant who alternately activated the BAS and the BIS while a game was played. The behaviour of the children was analysed according to ethological methods. Group differences in the frequencies of three out of five behavioural categories were in line with the results of the door-opening task ( $\mathrm{NC}<\mathrm{CD}<\mathrm{CD} / \mathrm{ADHD})$.
\end{abstract}

Keywords: Hyperactivity, aggression, conduct disorder, ethology, impulsivity, social behaviour.

Abbreviations: ADHD: attention deficit hyperactivity disorder; BAS: Behavioural Activation System; BIS: Behavioural Inhibition System; CBCL: Child Behavior Checklist; CD: conduct disorder; FFS: Fight/Flight System; NC: normal control.

\section{Introduction}

Conduct disordered (CD) children seem to become more actively involved with their environment than do normal children. This orientation toward action is reflected in the way they perceive their peers, i.e. more in terms of activities, than do their normal agemates (Matthys, Walterbos, Van Engeland, \& Koops, 1995). Not only do CD children become more easily mobilised (behavioural activation), but they also have more difficulty in stopping their ongoing behaviour (behavioural inhibition): they are more dependent on

Requests for reprints to: Walter Matthys, MD, PhD, Department of Child and Adolescent Psychiatry, University Hospital Utrecht, PO Box 85500, 3508 GA Utrecht, The Netherlands (E-mail: wmatthys@psych.azu.nl). their parents and teachers to restrain them than are normal children. To study these behavioural characteristics Quay (1993) suggested using Gray's $(1982,1987)$ psychobiological theory of personality as a starting point.

According to Gray's theory (1982, 1987, 1994), behaviour is mediated by the activity of three subsystems of the brain: the Behavioural Activation System (BAS), the Behavioural Inhibition System (BIS), and the Fight/ Flight System (FFS). The BAS activates behaviour in response to cues for probable reward and nonpunishment. The BIS inhibits ongoing behaviour in the presence of cues for probable punishment and nonreward. The FFS responds to unconditioned aversive stimuli with unconditioned defensive aggression and escape behaviour. The BIS and the BAS are antagonistic to each other and therefore behaviour that is not dependent on unconditioned stimuli results from the 
relative balance of the two systems. According to Gray, individual differences in personality are accounted for by variations in the relative strength of the two systems: individuals with a BAS that is relatively stronger than the BIS are impulsive, whereas those with the opposite imbalance are anxiety prone.

With respect to externalising disorders in childhood, Quay (1988a,b, 1993) suggested that attention deficit hyperactivity disorder (ADHD) and CD reflect different problems in the functioning of the BAS and the BIS. ADHD is characterised by an underactive BIS, whereas $\mathrm{CD}$ is associated with a BAS that dominates over the BIS: when cues for both reward and punishment are present, $C D$ children focus on cues for reward at the expense of cues for punishment. In other words, when both systems are activated, the BIS in CD is unable to interrupt the ongoing activity of the BAS; however, when only the BAS is activated, CD children do not overrespond (see also Milich, Hartung, Martin, \& Haigler, 1994). Finally, Quay (1993) hypothesises that because the presence of anxiety is indicative of activity of the BIS, the degree of dominance of the BAS over the BIS would be less in anxious $\mathrm{CD}$ children than in nonanxious $\mathrm{CD}$ children.

To test the dominance of the BAS over the BIS in CD children and adolescents, Quay and colleagues (Shapiro, Quay, Hogan, \& Schwartz, 1988), in a first study, used a computerised card-playing task that was developed by Siegel (1978) and adapted by Newman, Patterson, and Kosson (1987) for the study of response perseveration in adults. Response perseveration has been defined by McCleary (1966) as the tendency to continue a response set for reward despite punishment. In the computerised card-playing task used by Newman et al. (1987), there is a steadily increasing ratio of punished responses (BIS activation) to rewarded responses (BAS activation); thus, in order to avoid punishment subjects have to inhibit a previously rewarded response. The number of cards played before terminating the task is considered as a measure of response perseveration. Newman et al. found that psychopaths evidenced more response perseveration than did nonpsychopaths; in other words, psychopaths behaved as if their increased sensitivity to cues for reward led to decreased attention to the cues for punishment, a characteristic that has also been called reward dominance. In line with this result in adults, the CD group in the Shapiro et al. (1988) study (mean age of subjects, 13.9 years) showed more response perseveration (played more cards) than the non-CD group.

This dominance of the BAS over the BIS in CD has been confirmed in younger $\mathrm{CD}$ boys (mean age, 9.8 years) by Fonseca and Yule (1995), who used an adapted version of the computerised cards game used by Newman et al. (1987). On the other hand, in a task similar to the computerised response perseveration task (the dooropening task) developed by Daugherty and Quay (1991), O'Brien, Frick, and Lyman (1994) did not find differences between a group of disruptive behaviour disordered boys (mean age, 11 years) and normal controls. However, significant group differences emerged when measures of anxiety were included in the analysis; group differences thus were obscured by a number of disruptive behaviour disordered boys who also exhibited high levels of anxiety.
This result was confirmed in a second study (O'Brien \& Frick, 1996): children with severe conduct problems exhibited a reward-dominant response style only in the absence of a comorbid anxiety disorder. These findings are consistent with Gray's theory $(1982,1987,1994)$. In anxious behaviour-disordered boys the imbalance between the BIS and the BAS is restored in part: dominance of the BAS over the BIS (a CD characteristic) is countered by a relatively strong BIS (a characteristic of anxiety disorder).

Of particular relevance for the present investigation is the study by Daugherty and Quay (1991), which involved not only a $C D$ group but also a $C D$ group comorbid with ADHD. To study reward dominance in children aged 8 to 13 years, Daugherty and Quay designed a computerised response perseveration task, i.e. the door-opening task. In this task, the subject chooses either to open the next door or to stop playing; there is a steadily increasing ratio of punished responses to rewarded responses and a large number of doors opened is indicative of response perseveration. As the authors predicted, compared with normal controls, subjects with $\mathrm{CD}$ or $\mathrm{CD}$ associated with ADHD (CD/ADHD) opened significantly more doors. Surprisingly, the authors did not predict that the CD/ ADHD group would open more doors than the CD group. Indeed, according to Quay's (1988a, b) hypothesis of the underactive BIS characteristic of ADHD and the dominance of the BAS over the BIS characteristic of CD, the comorbid group would open more doors than the CD group: in CD/ADHD the BIS has even more difficulty in interrupting the ongoing BAS activity than in $\mathrm{CD}$, since in CD/ADHD not only does the BAS dominate over the BIS (a CD characteristic) but the BIS is also persistently underactive (an ADHD characteristic). In other words, the dominance of the BAS over the BIS should be found more clearly in CD/ADHD than in CD. According to Quay's hypothesis, response perseveration thus would be more clearly present in $\mathrm{CD} / \mathrm{ADHD}$ than in $\mathrm{CD}$. This, however, was not found in the Daugherty and Quay (1991) study.

The aim of the present study was to test the hypothesis that the dominance of the BAS over the BIS is more pronounced in CD/ADHD than in CD. Three groups of school-aged boys were involved: a normal control (NC) group, a CD group, and a CD/ADHD group. The study consisted of two parts. Firstly, a response perseveration task was used, i.e. the door-opening task designed by Daugherty and Quay (1991). We predicted a steady increase in the number of doors opened across the three groups ( $\mathrm{NC}<\mathrm{CD}<\mathrm{CD} / \mathrm{ADHD}$ ) before subjects quit. The difference between the present study and the Daugherty and Quay study is that in the latter study subjects were selected on the basis of behavioural ratings, whereas in our study subjects were defined psychiatrically, i.e. they met DSM-IV criteria of CD and/or ADHD (American Psychiatric Association, 1994).

In the second part of our study, we investigated whether the dominance of the BAS over the BIS, which we expected to be more pronounced in children with $\mathrm{CD}$ / ADHD than in children with CD, also becomes apparent in social behaviour. To this end, the child's behaviour was observed systematically while he played a cooperative game with a research assistant. During the game the 
research assistant alternately activated the BAS and the BIS by praising the child (reward), criticising him (punishment), or giving neutral feedback (nonreward, nonpunishment). The ethological methods used were ones that have been found to be successful in differentiating the social behaviour of $\mathrm{CD}$ and $\mathrm{NC}$ children while they play games (Matthys, De Vries, et al., 1995; Matthys, Van Loo, et al. 1995). We expected a higher frequency of social behaviour in CD/ADHD boys than in CD boys.

\section{Materials and Methods}

\section{Subjects}

Subjects consisted of boys with CD $(N=11)$, boys with CD associated with ADHD (CD/ADHD) $(N=10)$, and normal control boys (NC) $(N=31)$. The NC boys were recruited from a regular primary school; boys with scores in the clinical range on the Child Behavior Checklist (CBCL) (Achenbach, 1991; Verhulst, Berden, \& Sanders-Woudstra, 1985) were excluded. The CD and CD/ADHD boys came from an inpatient unit of the Department of Child and Adolescent Psychiatry, Utrecht University Hospital, and from a special school for severely behaviour-disordered children. Boys were placed in $\mathrm{CD}$ or $\mathrm{CD} / \mathrm{ADHD}$ groups on the basis of the strict application of DSM-IV criteria (American Psychiatric Association, 1994); consensus on the diagnosis was reached between two psychiatrists (WM, HvE). Boys with diagnoses of CD $(N=10)$ or oppositional defiant disorder $(N=11)$ were included in the $\mathrm{CD}$ group (with or without ADHD). It was permissible to include children with an oppositional defiant disorder in the CD group since the overlap in symptomatology is large between the childhood-onset type of conduct disorder and oppositional defiant disorder (Hinshaw, Lahey, \& Hart, 1993). To be included in the CD/ADHD group CD boys also satisfied the DSM-IV criteria for a concurrent attention-deficit/ hyperactivity disorder. $\mathrm{CD}$ and $\mathrm{CD} / \mathrm{ADHD}$ boys did not meet the criteria for any anxiety disorder. Because of the possible effect of intelligence on the methods used, boys with IQs of less than 75 were excluded.

Diagnoses of the inpatient subjects were based on extensive semistructured psychiatric interviews, psychological assessment of the child, interviews with the parents, including discussion of the developmental history, and observations by child-care workers. This information was gathered in an 8-week clinical assessment period, during which psychiatrists and residents provided feedback on the diagnoses every 2 weeks on the basis of discussions of accumulated case information. In the special school, diagnoses were based on a semistructured psychiatric interview with the child (Child Assessment Schedule; Hodges, Kline, Stern, Cytryn, \& McKnew, 1982) and an interview with the child's teacher conducted by a graduate educational psychologist.

In order to describe subjects from a dimensional point of view, the CBCL (Achenbach, 1991; Verhulst et al., 1985) was completed by each subject's primary caretaker. Also, subjects were administered the Wechsler Intelligence Scale for ChildrenRevised (WISC-R; Wechsler, 1974).

Descriptive characteristics of the sample are included in Table 1. The three groups did not differ in age and intelligence. On the CBCL, the CD/ADHD boys were rated as having more attention problems than the $\mathrm{CD}$ boys, and the $\mathrm{CD}$ boys were rated as having more attention problems than the $\mathrm{NC}$ boys. Also, according to their parents, CD/ADHD boys and CD boys were more aggressive, more delinquent, and more anxious/depressed than the NC boys.

The study protocol was approved by the Utrecht University Hospital Committee for Research On Human Subjects, and parents gave written informed consent. During testing, subjects were drug free.

\section{The Door-opening Task}

This task consists of a series of 110 doors presented sequentially on a MacIntosh computer in a preprogrammed order of winning and losing doors (Daugherty \& Quay, 1991). In this task the probability of a winning door appearing decreases by $10 \%$ with each succeeding set of 10 doors (thus from $100 \%$ to $0 \%$ ). Within each set of 10 doors, losing doors are randomly sequenced among winning doors. The dependent measure was the total number of doors opened before subject quit (Range $0-110)$.

The following instructions were given (Daugherty \& Quay, 1991).

In this game, you will see a number of doors on the computer screen - they will appear one at a time. Behind some of the doors are happy faces, and behind some of the doors are sad faces. Do you understand so far?

You will see only one door at a time, and the door will have a question mark on it. The door will look like this (pointing to the example on the screen). You can take a chance and open the door by pressing this bar (pointing to the space bar). If a happy face is behind the door, you will win a dime. If a sad face is behind the door, you will lose a dime. Let's try it (pressing the bar). That's a happy face; if I were playing, I would win a dime. OK so far?

You must open the doors in the order that the computer presents them to you. You cannot skip any doors; but you can stop playing any time you want by telling me that you

Table 1

Characteristics of Sample

\begin{tabular}{|c|c|c|c|c|c|c|c|c|}
\hline \multirow[b]{2}{*}{ Measure } & \multicolumn{2}{|c|}{$\begin{array}{c}\mathrm{NC} \\
(N=31)\end{array}$} & \multicolumn{2}{|c|}{$\begin{array}{c}\mathrm{CD} \\
(N=11)\end{array}$} & \multicolumn{2}{|c|}{$\begin{array}{l}\text { CD/ADHD } \\
(N=10)\end{array}$} & \multirow{2}{*}{$\begin{array}{c}\text { One-way } \\
\text { analysis } \\
F(2,49)\end{array}$} & \multirow{2}{*}{$\begin{array}{l}\text { Scheffé } \\
\alpha=.05\end{array}$} \\
\hline & Mean & $S D$ & Mean & $S D$ & Mean & $S D$ & & \\
\hline Age (years) & 9.6 & 1.1 & 10.4 & 1.0 & 10.0 & 1.2 & 2.13 & \\
\hline IQ (WISC-R) & 98 & 11 & 96 & 12 & 90 & 11 & 2.13 & \\
\hline \multicolumn{9}{|l|}{ CBCL (T scores) } \\
\hline Attention problems & 53.4 & 6.0 & 59.7 & 7.7 & 67.9 & 10.4 & $15.22 *$ & $\mathrm{CD} / \mathrm{ADHD}>\mathrm{CD}>\mathrm{NC}$ \\
\hline Aggressive behaviour & 52.1 & 3.9 & 65.3 & 11.9 & 71.6 & 14.9 & $22.07^{*}$ & $\mathrm{CD} / \mathrm{ADHD}=\mathrm{CD}>\mathrm{NC}$ \\
\hline Delinquent behaviour & 52.5 & 5.1 & 62.2 & 10.4 & 76.2 & 11.2 & $13.16^{*}$ & $\mathrm{CD} / \mathrm{ADHD}=\mathrm{CD}>\mathrm{NC}$ \\
\hline Anxious/Depressed & 52.8 & 5.1 & 70.4 & 8.6 & 68.4 & 13.3 & $27.46^{*}$ & $\mathrm{CD} / \mathrm{ADHD}=\mathrm{CD}>\mathrm{NC}$ \\
\hline
\end{tabular}

$* p<.001$. 
want to stop. Once you stop, you can keep all the dimes you have earned. Do you have any questions before we start? Remember, you have to tell me when you want to stop.

One difference from the procedure of Daugherty and Quay (1991) is that their subjects began with 10 chips, whereas in our procedure subjects won their first 10 dimes.

\section{Behavioural Observation}

Using a plan and a large number (195) of animal figures, the child was asked to construct a zoo that both the child and the research assistant would like. The figures were divided between the two participants, the child receiving red animals only and the research assistant green only. During the game, which took 13 minutes, each move of the child was consistently commented on (reinforced) by the research assistant. In the following reinforcement blocks the BAS and the BIS were activated alternately according to Gray's (1994) operational definitions of the BAS and the BIS: (1) first reward (BAS): the research assistant praised every move of the child for 3 minutes; (2) punishment (BIS): the research assistant criticised every move of the child for 3 minutes; (3) nonpunishment (BAS): the research assistant commented in a neutral way on the moves of the child for 2 minutes; (4) second reward (BAS): the research assistant praised every move of the child for 3 minutes; (5) nonreward (BIS): the research assistant commented in a neutral way on the moves of the child for 2 minutes. All the sessions were videotaped. The tapes were timecoded with a Video Timecode Generator. The videotapes were analysed afterwards by means of a computerised behavioural analysis program "Observer" (Noldus, 1992). This was done according to an ethogram, which was used in an earlier study (Matthys, De Vries, et al., 1995) and slightly changed for the present purposes. For the analyses, 22 behavioural elements were divided into 5 categories on the dimension prosocial-antisocial behaviour: clearly prosocial (e.g. act in an interested way), moderately prosocial (e.g. ask permission), neutral (e.g. express oneself), moderately antisocial (e.g. urge), clearly antisocial (e.g. denigrate). Inter-observer reliability of the scoring of behavioural elements and behavioural categories was computed between 2 trained observers in 11 randomly chosen sessions; mean interobserver reliability for behavioural elements was $77 \%$, and for behavioural categories it was $81 \%$. We checked whether the research assistants performed the scripted procedure for the reinforcement blocks. Ethological data could not be obtained from six NC boys for technical reasons.

\section{Procedure}

The two test conditions formed part of a longer experimental session (Van Goozen et al., in press) that took place between $9.00 \mathrm{am}$ and $11.30 \mathrm{am}$ in a playroom of the Department of Child and Adolescent Psychiatry, Utrecht University Hospital. The door-opening task was administered at the beginning of the session and the behavioural observation took place at the end of the session, with about 1.5 hours in between. The research assistant and scorers were blind to the child's group status. Subjects were administered the WISC-R on a separate occasion to the main experiment.

\section{Data Analysis}

In the door-opening task, the prediction that there will be a steady increase in the number of doors opened across the three groups was tested using an ANOVA with Group as the betweensubjects factor and the linear contrast across the three groups.
In the behavioural study, we first tested whether the reinforcement conditions affected the frequencies of the behavioural categories. Second, we tested the linear contrast of the total frequencies of the behavioural categories over the various reinforcement conditions across the three groups. Third, in order to examine whether the three groups differed in the way the behavioural categories were affected by the reinforcement conditions, we tested the interactions between reinforcement and the frequencies of behavioural categories in the three groups. For these tests, a multivariate approach consisting of a repeated measures ANOVA (Wilks' Lambda) was used with Reinforcement Condition as a within-subjects factor, Group as a between-subjects factor, and the interaction between Reinforcement Condition and Group.

\section{Results}

\section{Door-opening Task}

The means of the number of doors opened are shown in Table 2 . The results of the analysis of variance revealed a significant univariate effect for Group $[F(2,49)=6.10$, $p<.005]$. The hypothesis of a steady increase in the number of doors opened across the three groups ( $\mathrm{NC}<\mathrm{CD}<\mathrm{CD} / \mathrm{ADHD}$ ) was tested by examining the linear contrast across the three groups. This contrast was significant (linear contrast, $t=12.02, p<.001$ ).

Because the CD group differed significantly from the NC group not only in CBCL aggressive behaviour scores (Table 1) (i.e. behaviour characteristic of CD), but also in CBCL attention problem scores (Table 1) (i.e. behaviour characteristic of ADHD), the difference in performance might be attributed not so much to a factor thought to be associated with CD (dominance of the BAS over the BIS) as a factor thought to be associated with ADHD (underactive BIS). Therefore, Spearman correlation coefficients were computed between the number of doors opened on the one hand and CBCL aggressive behaviour and CBCL attention problems scores on the other. The Spearman correlation coefficient between the number of doors opened and CBCL aggressive behaviour was .35 $(p<.05)$, and between the number of doors opened and attention problems it was .43 $(p<.01)$. Spearman correlation coefficient between CBCL aggressive behaviour and attention problems was $.79(p<.001)$. Thus, both aggressive behaviour and attention problems were associated with the task performance variable. However, when task performance was regressed onto attention problems and aggressive behaviour simultaneously, aggressive behaviour did not add significantly to the variance explained by attention problems; nor did attention problems and aggressive behaviour interact in predicting task performance.

Table 2

Means and Standard Deviations for the Three Groups in the Door-opening Task

\begin{tabular}{lccc}
\hline \multirow{2}{*}{ Number of doors opened } & \multicolumn{3}{c}{ Groups } \\
\cline { 2 - 4 } Mean & NC & CD & CD/ADHD \\
SD & 57.9 & 71.6 & 93.6 \\
\hline
\end{tabular}


Table 3

Means of Frequencies of Behavioural Categories for the Three Groups and Results of Repeated Measures ANOVAs (Wilks' Lambda) with Reinforcement and Group (Linear Contrast of Total Frequencies) as Factors, and the Interactions between Reinforcement and Group

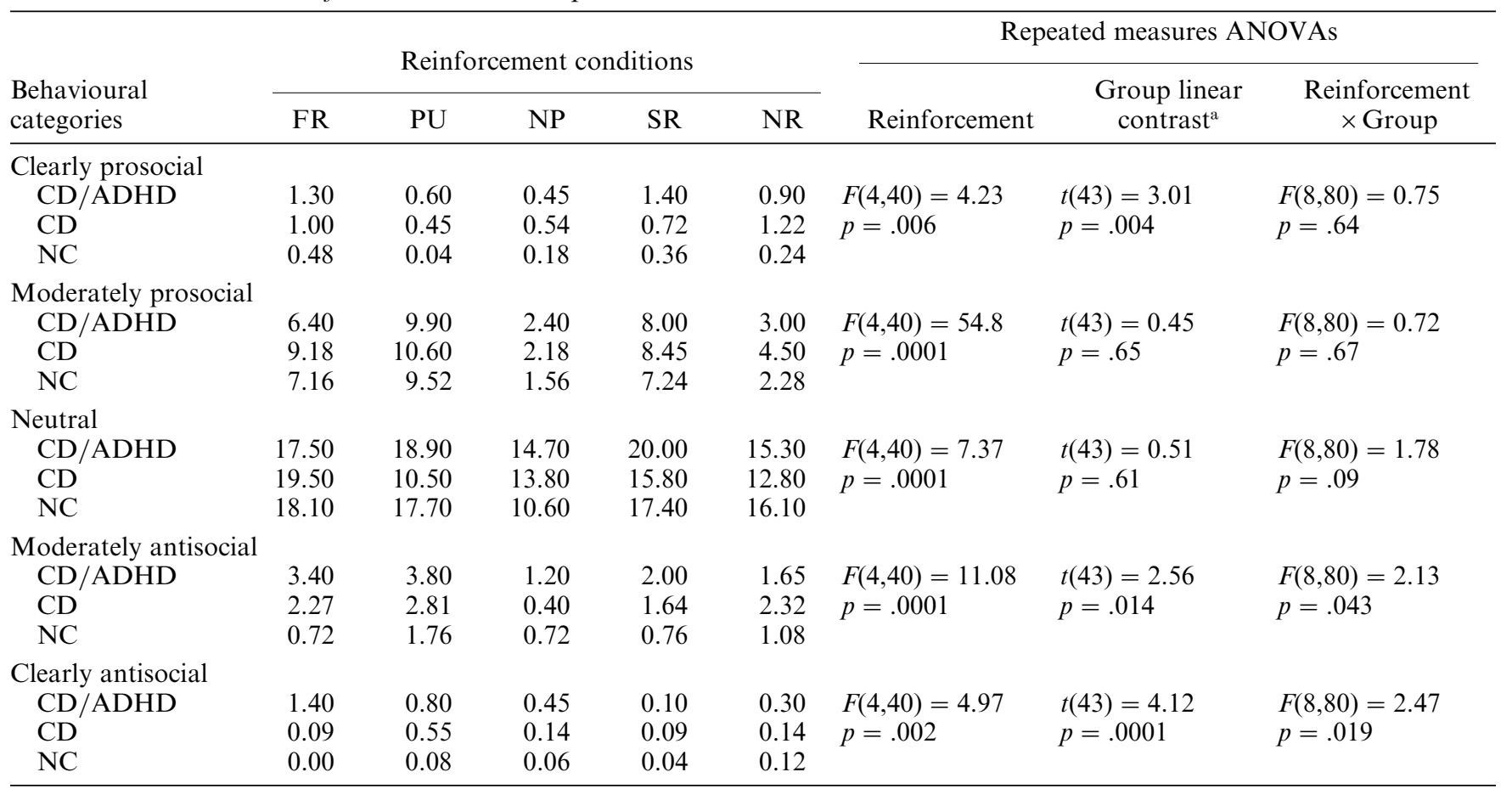

$\mathrm{FR}=$ first reward, $\mathrm{PU}=$ punishment, $\mathrm{NP}=$ nonpunishment, $\mathrm{SR}=$ second reward, $\mathrm{NR}=$ nonreward.

${ }^{\text {a }}$ Group linear contrast of total frequencies $=\mathrm{CD} / \mathrm{ADHD}>\mathrm{CD}>\mathrm{NC}$.

Because the mean CBCL anxiety/depressed scores for the $\mathrm{CD}$ and $\mathrm{CD} / \mathrm{ADHD}$ groups were relatively high (Table 1), and because of the possible moderating effect of anxiety on response perseveration (O'Brien \& Frick, 1996; O'Brien et al., 1994), we next examined whether anxiety had a mediating effect on the number of doors opened. First of all, the correlation between CBCL anxious/depressed scores across all three groups and the number of doors opened was computed. The Spearman correlation coefficient was .23 (n.s.); after removal of one outlier, the correlation coefficient was .21 (n.s.). Second, we tested whether high-anxious CD boys differed from low-anxious $\mathrm{CD}$ boys in the number of doors they opened. For this, we collapsed both CD groups (CD and $\mathrm{CD} / \mathrm{ADHD}$ ) and divided them into high-anxious $\mathrm{CD}$ boys $(N=12 ; M=76.2, S D=9.1)$ and low-anxious $C D$ boys $(N=9 ; M=60.4, S D=4.6)$, based on a cut-off score of 67. The difference in the number of doors opened by the high-anxious $\mathrm{CD}$ boys $(M=82.1, S D=32.5)$ and by the low-anxious $C D$ boys $(M=82.0, S D=30)$ was not significant $[F(1,19)=0.01, p=1.0]$.

\section{Behavioural Observation}

The means of frequencies of the five behavioural categories (clearly prosocial, moderately prosocial, neutral, moderately antisocial, clearly antisocial) for the three groups $(\mathrm{CD} / \mathrm{ADHD}, \mathrm{CD}, \mathrm{NC})$ in the five reinforcement conditions (first reward, punishment, nonpunishment, second reward, nonreward) and results of the repeated measures ANOVA (Wilks' Lambda) are presented in Table 3.

First of all, a clear effect of reinforcement on the frequencies of the five behavioural categories over the three groups was found. Thus, the research assistant succeeded in affecting the boys' behaviour through reinforcement manipulations. Second, the linear contrast in the total frequencies of five behavioural categories (i.e. the sum of the frequencies of each behavioural category over the five reinforcement conditions) across the three groups was significant for three out of five behavioural categories (clearly prosocial, moderately antisocial, clearly antisocial) with, as expected, $\mathrm{CD} / \mathrm{ADHD}$ boys showing these behavioural categories more frequently than $\mathrm{CD}$ boys, and $\mathrm{CD}$ boys showing these behavioural categories more frequently than NC boys. Third, a significant interaction effect between reinforcement and group was found for moderately antisocial and clearly antisocial behaviour. No clear pattern of an overactive BAS or underactive BIS in $\mathrm{CD}$ or $\mathrm{CD} / \mathrm{ADHD}$ groups could be identified.

Just as in the door-opening task, we examined whether the differences between the three groups in the total frequencies of three out of five behaviour categories (clearly prosocial, moderately antisocial, clearly antisocial) might be attributed to a factor associated with CD (dominance of the BAS over the BIS) or to a factor associated with ADHD (underactive BIS). Therefore, 
Spearman correlation coefficients were computed between the total frequencies of the behavioural categories and both CBCL aggressive behaviour and CBCL attention problems scores. The correlation coefficients between clearly prosocial behaviour, moderately antisocial behaviour, and clearly antisocial behaviour on the one hand, and CBCL aggressive behaviour on the other hand were $.30(p<.05), .29(p<.05)$, and $.58(p<$ $.001)$, respectively. The correlation coefficients between clearly prosocial behaviour, moderately antisocial behaviour, and clearly antisocial behaviour on the one hand and CBCL attention problems on the other hand were .24 $(p<.10), .40(p<.01)$, and $.44(p<.01)$, respectively. Thus both CBCL aggressive behaviour (a behavioural indicator of dominance of the BAS over the BIS) and CBCL attention problems (a behavioural indicator of an underactive BIS) were associated with the frequencies of the three behavioural categories on which the groups differed. Scores on clearly prosocial behaviour, moderately antisocial behaviour, and clearly antisocial behaviour were entered into a multiple regression analysis, using aggressive behaviour and attention problems scores as predictors. Together these variables accounted for $12.35 \%$ of the variance in clearly prosocial behaviour, $F(2,43)=3.03, p<.06$. The beta weights showed that whereas attention problems scores approached significance as a predictor of clearly prosocial behaviour (beta $=.48, p<.055)$, aggressive behaviour scores were not a significant predictor (beta $=-.18$ ). Aggressive behaviour and attention problems scores together accounted for $21.78 \%$ of the variance in moderately antisocial behaviour, $F(2,43)=5.99, p<.01$. The beta weights showed that neither variable achieved statistical significance as a predictor. Aggressive behaviour and attention problems scores together accounted for $24.26 \%$ of the variance in severely antisocial behaviour, $F(2,43)$ $=6.89, p<.01$. The beta weights showed that aggressive behaviour scores were a marginally significant predictor (beta $=.39, p=.09$ ); attention problem scores did not achieve statistical significance as a predictor.

Although the two parts of the study differed from each other in the sequence of the BAS/BIS activations, both tasks were intended to measure the imbalance between the BAS and the BIS. Spearman correlation coefficients between the numbers of doors opened and the total frequencies of the three behavioural categories in which the groups differed were computed. For clearly prosocial behaviour the correlation coefficient was .21 $(p=.08)$, for moderately antisocial behaviour it was $.27(p=.03)$, and for clearly antisocial behaviour it was $.21(p=.08)$. The associations between the different operationalisations were thus positive but low.

\section{Discussion}

Two studies were conducted to test the hypothesis that the dominance of the BAS over the BIS is more prominent in $\mathrm{CD}$ comorbid with ADHD (CD/ADHD) than in CD alone. First, a response perseveration task was used, i.e. the door-opening task (Daugherty \& Quay, 1991). The results of this task confirmed the prediction of a steady increase in the number of doors opened across $\mathrm{NC}, \mathrm{CD}$, and $\mathrm{CD} / \mathrm{ADHD}$ boys $(\mathrm{NC}<\mathrm{CD}<\mathrm{CD} / \mathrm{ADHD})$. The finding that response perseveration, being the tendency to continue a response set for reward despite punishment, was more pronounced in the $\mathrm{CD} / \mathrm{ADHD}$ group than in the $\mathrm{CD}$ group adds to a growing body of research that suggests that the functioning of $\mathrm{CD} / \mathrm{ADHD}$ children is more impaired than the functioning of $\mathrm{CD}$ children, and that the long-term outcome of CD/ADHD children is more negative than that of CD children (e.g. Farrington, Loeber, \& Van Kammen, 1990; Moffit, 1993; Taylor, 1994; Taylor, Sandberg, Thorley, \& Giles, 1991; Walker, Lahey, Hynd, \& Frame, 1987).

These findings concerning response perseveration provide support for Quay's (1993) hypothesis derived from Gray's theory (1982, 1987) regarding BAS-BIS functioning in children with externalising symptomatology: the imbalance between the BAS and the BIS, i.e. dominance of the BAS over the BIS, should be found more clearly in CD/ADHD than in CD. This is because in $\mathrm{CD} / \mathrm{ADHD}$ the BIS has even more difficulty in interrupting the ongoing BAS activity than in $\mathrm{CD}$, since in $\mathrm{CD} / \mathrm{ADHD}$ not only does the BAS dominate over the BIS (a CD characteristic) but the BIS is also persistently underactive (an ADHD characteristic).

There is, however, an alternative interpretation of the findings: differences between the three groups in performance in the response perseveration task might be attributed mainly to an underactive BIS. In our sample, the $\mathrm{CBCL}$ attention problems scores of the three groups differed significantly from each other $(\mathrm{NC}<\mathrm{CD}<$ $\mathrm{CD} / \mathrm{ADHD}$ ). If the $\mathrm{CBCL}$ attention problem score is a behavioural indicator of an underactive BIS, then group differences in response perseveration $(\mathrm{NC}<\mathrm{CD}<$ $\mathrm{CD} / \mathrm{ADHD}$ ) might be caused only by an underactive BIS. This interpretation is supported by the fact that the correlation coefficient between CBCL attention problem scores and the number of doors opened (.43) is higher than between the CBCL aggressive behaviour scores and the number of doors opened (.35). Moreover, when task performance was regressed onto attention problems and aggressive behaviour simultaneously, aggressive behaviour did not add significantly to the variance explained by attention problems; nor did attention problems and aggressive behaviour interact in predicting task performance. Thus, in our sample differences in response perseveration might be attributed more probably to an underactive BIS than to dominance of the BAS over the BIS. However, it is uncertain whether a CBCL attention problems score is an adequate behavioural indicator of an underactive BIS.

The difference in response perseveration between our $C D$ and $C D / A D H D$ groups was not found in the Daugherty and Quay (1991) study, probably because their sample differed from ours. In the Daugherty and Quay study subjects were recruited from regular primary schools and were selected on the basis of behaviour ratings, whereas in our study we used subjects from an inpatient psychiatric unit as well as pupils from a special school for severely behaviour-disordered children. Psychopathology may have been more pronounced in our sample leading to more pronounced group differences.

A striking finding is that groups differed in response perseveration despite significantly higher levels of anxiety in $\mathrm{CD}$ and $\mathrm{CD} / \mathrm{ADHD}$ boys than in NC boys. In the two 
studies conducted by Quay and colleagues (Daugherty \& Quay, 1991; Shapiro et al., 1988), only CD children without elevations on the anxiety scale were involved; thus, the influence of anxiety on task performance in CD children could not be investigated in these studies. However, this was possible in the two studies by O'Brien and colleagues (O'Brien \& Frick, 1996; O'Brien et al., 1994) and in our study. In the O'Brien studies differences between the disruptive behaviour disordered/conduct problem children and the normal controls were found only in the nonanxious subjects. These authors concluded that in the anxious behaviour disordered boys the imbalance between the BIS and the BAS is restored: dominance of the BAS over the BIS (a CD characteristic) is countered by a relatively strong BIS (a characteristic of anxiety disorder). In our study, the groups studied differed significantly in response perseveration, despite elevated levels of anxiety in both $\mathrm{CD}$ and $\mathrm{CD} / \mathrm{ADHD}$, and high-anxious $\mathrm{CD}$ boys did not differ from lowanxious $\mathrm{CD}$ boys. Moreover, there was no meaningful relation between CBCL anxious/depressed scores and the number of doors opened in the whole sample. Anxiety thus seems to have had no effect on response perseveration in our study, and this finding is not consistent with Gray's $(1982,1987,1994)$ theory. In this context it should be mentioned that findings concerning the effect of anxiety on response perseveration are equivocal. In the O'Brien and Frick (1996) study, contrary to expectation, children with an anxiety disorder did not differ significantly from normal control children in response perseveration. In the Daugherty and Quay (1991) study there was a small difference in perseverative responding between anxious children and normal controls but, though the difference was not tested, it did not seem to reach significance.

The results of the response perseveration task have been interpreted from the perspective of the dominance of the BAS over the BIS. However, there are alternative interpretations of perseverative responding, e.g. as a deficiency in response modulation (Newman \& Wallace, 1993). Response modulation is an automatic process according to which a person interrupts ongoing behaviour in response to feedback from the environment or information arising from internal associations (Newman \& Wallace, 1993). Perseverative responding is related to processing limitations that interfere with a person's ability to assimilate unattended but potentially relevant information (e.g. the increasing probability of punishment in a response perseveration task) while the person is engaged in the organisation and implementation of goaldirected behaviour (Newman \& Wallace, 1993). From a response modulation perspective the fact that response perseveration is more pronounced in $\mathrm{CD} / \mathrm{ADHD}$ boys than in $\mathrm{CD}$ boys might be related to the more severe processing limitations of $\mathrm{CD} / \mathrm{ADHD}$ boys.

In the second study we examined whether the dominance of the BAS over the BIS in CD, which is even more pronounced in $\mathrm{CD} / \mathrm{ADHD}$, would also become apparent in social behaviour. In contrast with the door-opening task, in which rewards and punishment competed with each other, in the behavioural study the BAS and the BIS were activated alternately.

Reinforcement conditions affected the frequencies of all five behavioural categories. Fluctuations in the frequencies of behavioural categories were often in line with predictions, e.g. an increase in most categories from nonpunishment to second reward (BAS activation), and a decrease in most categories from second reward to nonreward (BIS activation). However, changes in frequencies from first reward to punishment (BIS activation) differed between behavioural categories. Criticism not only evoked an expected decrease in clearly prosocial behaviour (e.g. treat kindly) but also an unexpected increase in moderately prosocial behaviour (e.g. comply), the latter probably expressing a need for reconciliation. Also, criticism evoked an unexpected increase in moderately antisocial behaviour (e.g. express discontent), which probably expresses resistance. Clearly, in contrast with responses to reinforcement conditions elicited in a computerised test, responses elicited in the more complex conditions of dyadic interactions depend not only on behavioural activation and inhibition but also on other factors, e.g. the function of particular behaviours in the regulation of a dyadic relationship.

The linear contrast between the total frequencies of behavioural categories (i.e. the sum of the frequencies of each behavioural category over the five reinforcement conditions) across the three groups was significant for the behavioural categories clearly prosocial, moderately antisocial, and clearly antisocial, with CD/ADHD boys showing these behaviours more frequently than $\mathrm{CD}$ boys, and $\mathrm{CD}$ boys showing these behaviours more frequently than NC boys. What is striking is not so much the higher frequencies of both antisocial categories but the higher frequency of clearly prosocial behaviour, i.e. behaviour that one would not expect to occur more frequently in $\mathrm{CD}$ and $\mathrm{CD} / \mathrm{ADHD}$ than in NC boys. These findings can be interpreted as the result of the dominance of the BAS over the BIS in CD and the even clearer dominance of the BAS over the BIS in CD/ADHD. However, both the correlation coefficients between the frequencies of the three behavioural categories on the one hand, and the CBCL aggressive behaviour scores (a behavioural indicator of dominance of the BAS over the BIS) and the CBCL attention problem scores (a behavioural indicator of an underactive BIS) on the other hand, were positive and moderately low. Thus, we cannot rule out the possibility that the frequencies of the three behavioural categories are due to an underactive BIS. However, as stated earlier, it is uncertain whether a CBCL attention problems score is an adequate behavioural indicator of an underactive BIS and whether a CBCL aggressive behaviour score is an adequate behavioural indicator of dominance of the BAS over the BIS.

Differences between the three groups, demonstrated in the door-opening task, thus also became apparent in social behaviour. Correlations between the measures in both tasks were positive but low, possibly because of different BAS/BIS activations in the two studies. From the perspective of Newman's (Newman \& Wallace, 1993) response modulation hypothesis it might be argued that the changes in contingencies used in the behavioural observation study did not allow for a dominant response set to be formed to the same extent that such a set is encouraged in the door-opening task. The findings of the study must be interpreted with some caution because the 
study has some limitations. The number of subjects was small and a replication of the study is therefore necessary. Also, different diagnostic methods were used for children from the clinic and children from the special school. Finally, future studies should investigate whether the dominance of the BAS over the BIS in CD and CD/ ADHD children is caused by an overactive BAS, an underactive BIS, or by a combination of the two. Therefore, a reward-alone and a punishment-alone task should be used in addition to the door-opening task, and an ADHD group should be included as well as a CD and a CD/ADHD group.

Further research is also desirable since the outcomes of such studies may have important consequences for the treatment of CD children. Specifically, further insight into these children's responses to cues for probable reward and punishment may be relevant for the application of contingency management. Contingency management relies on the systematic control of the consequences of the behaviour that needs to be changed. Such programmes employ techniques to facilitate the development of appropriate behaviours in everyday life situations (e.g. reinforcement techniques such as praise) and procedures aimed at reducing or eliminating inappropriate behaviours (e.g. punishment techniques such as time-out and response cost). Contingency management is the most effective treatment method in CD, either applied within inpatient/residential treatment settings (Matthys, 1997) or as part of (behavioural) parent training given in outpatient clinics (Serkevitch \& Dumas, 1996; Webster-Stratton, 1991). If an underactive BIS plays an important part in the imbalance between the BAS and the BIS in CD and CD/ADHD, it follows that punishment procedures are necessary to activate an otherwise underactive BIS. There is some evidence that in $\mathrm{CD}$ reward alone is ineffective without the simultaneous use of mild punishment (Phillips, Phillips, Fixsen, \& Wolf, 1971; Wahler \& Fox, 1980).

Acknowledgements - The authors wish to express many thanks to Reinhout Wiers for his help in the preparation of the study. They would also like to thank Nathalie Thoonsen and Suzanne Rutgers for their help with data collection and analysis.

\section{References}

Achenbach, T. M. (1991). Manual for the Child Behavior Checklist/4-18 and 1992 Profile. Burlington, VT: University of Vermont, Department of Psychiatry.

American Psychiatric Association. (1994). Diagnostic and statistical manual of mental disorders (4th edn., DSM-IV). Washington, DC: Author.

Daugherty, T. K., \& Quay, H. C. (1991). Response perseveration and delayed responding in childhood behavior disorders. Journal of Child Psychology and Psychiatry, 32, 453-461.

Farrington, D. P., Loeber, R., \& Van Kammen, W. B. (1990). Long-term criminal outcomes of hyperactivity-impulsivityattention deficit and conduct problems in childhood. In L. N. Robins \& M. Rutter (Eds.), Straight and devious pathways from childhood to adulthood (pp. 62-81). Cambridge: Cambridge University Press.
Fonseca, A. C., \& Yule, W. (1995). Personality and antisocial behavior in children and adolescents: An enquiry into Eysenck's and Gray's theories. Journal of Abnormal Child Psychology, 23, 767-781.

Gray, J. A. (1982). The neuropsychology of anxiety: An inquiry into the function of the septohippocampal system. New York: Oxford University Press.

Gray, J. A. (1987). The psychology of fear and stress (2nd edn.). Cambridge: Cambridge University Press.

Gray, J. A. (1994). Framework for a taxonomy of psychiatric disorder. In S. H. M. van Goozen, N. E. van de Poll, \& J. A. Sergeant (Eds.), Emotions: Essays on emotion theory (pp. 29-59). Hillsdale, NJ : Lawrence Erlbaum.

Hinshaw, S. P., Lahey, B. J., \& Hart, E. L. (1993). Issues of taxonomy and comorbidity in the development of conduct disorder. Development and Psychopathology, 5, 31-49.

Hodges, K., Kline, J., Stern, L., Cytryn, L., \& McKnew, D. (1982). The development of a child assessment interview for research and clinical use. Journal of Abnormal Child Psychology, 10, 173-189.

Kruesi, M., Rapoport, J., Hamburger, S., Hibbs, E., Potter, W., Lenane, M., \& Brown, G. (1990). Cerebrospinal fluid monoamine metabolites, aggression, and impulsivity in disruptive disorders to children and adolescents. Archives of General Psychiatry, 47, 419-426.

Matthys, W. (1997). Residential behavior treatment for children with conduct disorders. Behavior Modification, 21, 512-532.

Matthys, W., De Vries, H., Hectors, A., Veerbeek, M., Heidemann, W., Goud, M., Van Hooff, J. A., \& Van Engeland, H. (1995). Differences between conduct disordered and normal control children in their tendencies to escalate and neutralize conflicts when interacting with normal peers. Child Psychiatry and Human Development, 26, 29-41.

Matthys, W., Van Loo, P., Pachen, V., De Vries, H., Van Hooff, J. A., \& Van Engeland, H. (1995). Behavior of conduct disordered children in interaction with each other and with normal peers. Child Psychiatry and Human Development, 25, 183-195.

Matthys, W., Walterbos, W., Van Engeland, H., \& Koops, W. (1995). Conduct disordered boys' perceptions of their liked peers. Cognitive Therapy and Research, 19, 357-372.

McCleary, R. (1966). Response-modulating function of the limbic system: Initiation and suppression. In E. Stellar \& J. Sprague (Eds.), Progress in physiological psychology, Vol. 1 (pp. 209-271). New York: Academic Press.

Milich, R., Hartung, C., Martin, C., \& Haigler, E. (1994). Behavioral disinhibition and underlying processes in adolescents with disruptive behavior disorders. In D. Routh (Ed.), Disruptive behavior disorders in childhood (pp. 109-138). New York: Plenum Press.

Moffit, T. E. (1993). The neuropsychology of conduct disorder. Development and Psychopathology, 5, 135-151.

Newman, J. P., Patterson, C. M., \& Kosson, D. S. (1987). Response perseveration in psychopaths. Journal of Abnormal Psychology, 96, 145-148.

Newman, J. P., \& Wallace, J. F. (1993). Diverse pathways to deficient self-regulation: Implications for disinhibitory psychopathology in children. Clinical Psychology Review, 13, 699-720.

Noldus, L. (1992). The Observer-Computer Software for Behavioural Research, Version 3.0: Instruction manual. Wageningen, The Netherlands: Noldus Information Technology.

O'Brien, B. S., \& Frick, P. J. (1996). Reward dominance: Associations with anxiety, conduct problems, and psychopathy in children. Journal of Abnormal Child Psychology, 24, 223-240.

O'Brien, B. S., Frick, P. J., \& Lyman, R. D. (1994). Reward dominance among children with disruptive behavior 
disorders. Journal of Psychopathology and Behavioral Assessment, 16, 131-145.

Phillips, E. L., Phillips, E. A., Fixsen, D. L., \& Wolf, M. M. (1971). Achievement place: Modification of the behaviors of pre-delinquent boys within a token economy. Journal of Applied Behavior Analysis, 4, 541-561.

Quay, H. C. (1988a). Theories of ADHD. Journal of the American Academy of Child and Adolescent Psychiatry, 27, 262-263.

Quay, H. C. (1988b). The behavioural reward and inhibition systems in childhood behavior disorder. In L. M. Bloomingdale (Ed.), Attention deficit disorder. Vol. 3 : New research in attention, treatment and psychopharmacology (pp. 176-186). Oxford: Pergamon Press.

Quay, H. C. (1993). The psychobiology of undersocialized aggressive conduct disorder: A theoretical perspective. Development and Psychopathology, 5, 165-180.

Rogeness, G. A., Javors, M. A., \& Pliszka, S. R. (1992). Neurochemistry and child and adolescent psychiatry. Journal of the American Academy of Child and Adolescent Psychiatry, 31, 765-781.

Serkevitch, W., \& Dumas, J. (1996). The effectiveness of behavioral parent training to modify antisocial behavior in children: A meta-analysis. Behavior Therapy, 27, 171-186.

Shapiro, S. K., Quay, H. C., Hogan, A. E., \& Schwartz, K. P. (1988). Response perseveration and delayed responding in undersocialized aggressive conduct disorder. Journal of $\mathrm{Ab}$ normal Psychology, 97, 371-373.

Siegel, R. (1978). Probability of punishment and suppression of behaviour in psychopathic and nonpsychopathic offenders. Journal of Abnormal Psychology, 87, 514-522.
Taylor, E. (1994). Syndromes of attention deficit and overactivity. In M. Rutter, E. Taylor, \& L. Hersov (Eds.), Child and adolescent psychiatry, modern approaches (3rd Edn.) (pp. 285-307). Oxford: Blackwell Scientific Publications.

Taylor, E., Sandberg, S., Thorly, G., \& Giles, S. (1991). The epidemiology of childhood hyperactivity. Maudsley monographs No. 33. Oxford: Oxford University Press.

Van Goozen, S., Matthys, W., Cohen-Kettenis, P., Gispen-de Wied, C., Wiegant, V., \& van Engeland, H. (in press). Salivary cortisol and cardiovascular arousal during stress in conduct disordered boys and normal controls. Biological Psychiatry.

Verhulst, F. C., Berden, G. F. M. G., \& Sanders-Woudstra, J. A. R. (1985). Mental health in Dutch children: II. The prevalence of psychiatric disorder and relationship between measures. Acta Psychiatrica Scandinavica, 72 (Suppl.), 342.

Wahler, R. G., \& Fox, J. J. (1980). Solitary toy play and time out: A family treatment package for children with aggressive and oppositional behavior. Journal of Applied Behavioral Analysis, 13, 23-39.

Walker, J. L., Lahey, B. B., Hynd, G. W., \& Frame, C. L. (1987). Comparison of specific patterns of antisocial behavior in children with conduct disorder with or without coexisting hyperactivity. Journal of Consulting and Clinical Psychology, $55,910-913$.

Webster-Stratton, C. (1991). Annotation: Strategies for helping families with conduct-disordered children. Journal of Child Psychology and Psychiatry, 32, 1047-1062.

Wechsler, D. (1974). Wechsler Intelligence Scale for ChildrenRevised. New York: Psychological Corporation.

Manuscript accepted 8 October 1997 